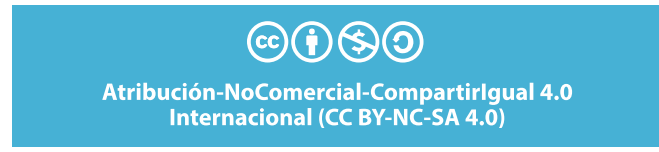

DOI: http://dx.doi.org/10.20983/reij.2021.2.8
Claudia Lizbeth Miramontes Ruiz ${ }^{1}$

FECHA DE RECEPCIÓN: 11 de diciembre 2020

FECHA DE ACEPTACIÓN: 20 de febrero 2021

\title{
LA PERSPECTIVA DE GÉNERO Y LOS OPERADORES DEL SISTEMA DE IMPARTICIÓN Y PROCURACIÓN DE JUSTICIA EN CIUDAD JUÁREZ, CHIHUAHUA
}

\author{
The gender perspective and the operators of the justice administration and enforcement \\ system in Ciudad Juarez, Chihuahua
}

\section{Resumen:}

La presente investigación tuvo como objeto analizar si los operadores del sistema de impartición y procuración de justicia en Ciudad Juárez, Chihuahua, en cumplimiento a la sentencia del "Campo Algodonero" emitida por la Corte Interamericana de Derechos Humanos en el año 2009, están verdaderamente preparados para atender con perspectiva de género los casos de mujeres transgénero. Este trabajo fue de tipo no experimental, transversal, descriptivo y de carácter cualitativo. Para ello se realizaron 32 entrevistas en las cuales los voluntarios fueron agentes del Ministerio Público, agentes de la Agencia Estatal de Investigación, agentes de la Comisión Estatal de Seguridad de la Fiscalía General del Estado y agentes Municipales de la Secretaria de Seguridad Pública. Pese a que se trata de información expuesta, el resultado fue que la mayoría de los participantes conoce el significado de juzgar con perspectiva de género y están conscientes de la histórica violencia en contra de la mujer en la ciudad, pero ello no supone que apliquen efectivamente dichos criterios en su área laboral y personal, pues algunos manifestaron no estar de acuerdo con la clasificación que hace el legislador de los delitos de género, limitándose a actuar conforme a lo que sugiere la costumbre.

Palabras clave: Perspectiva de género, instituciones, servidores públicos, seguridad pública, justicia.

\section{Abstract:}

The purpose of this investigation was to analyze whether the operators of the justice system in Ciudad Juárez, Chihuahua, in compliance with the Cotton Field Judgment issued by the Inter-American Court of Human Rights in 2009, are truly prepared to attend with a gender perspective the cases of transgender women. This work was non-experimental, transversal, descriptive and qualitative in nature. For this, 32 interviews were carried out in which the volunteers were agents of the Public Ministry, agents of the State Investigation Agency, agents of the State Security Commission of the Attorney General's Office and municipal agents of the Secretary of Public Security. Despite the fact that this information is exposed, the result was that most

1 Maestra en Gestión de Sistemas de Seguridad Pública por el Instituto Estatal de Seguridad Pública de Ciudad Juárez (México). Agente del Ministerio Público adscrita a la Fiscalía Especializada en Atención a Mujeres Víctimas del Delito por Razones de Género. Correo electrónico: c.miramontesr@gmail.com; https://orcid.org/0000-0002-5155-296X 
of the participants know the meaning of judging with a gender perspective and are aware of the historical violence against women in the city, but this does not mean that they effectively apply these criteria in their work and personal area, as some stated that they did not agree with the legislator's classification of gender crimes, limiting themselves to acting according to what custom suggests.

Keywords: Gender perspective, institutions, public servants, public safety, justice.

\section{Introducción}

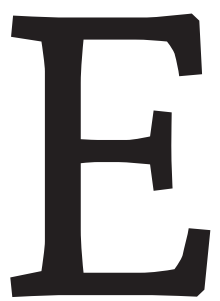

1 Estado mexicano fue condenando en el año 2009 por la Corte Interamericana de Derechos Humanos. La demanda se originó por la desaparición de Claudia Ivette González, Esmeralda Herrera Monreal y Laura Berenice Ramos Monárrez, quienes posteriormente fueron localizadas sin vida en el área denominada como Campo Algodonero en Ciudad Juárez, Chihuahua en el año 2001. La responsabilidad internacional del Estado mexicano recae, a grandes rasgos, en la falta de medidas de protección a las víctimas, la ausencia de respuesta por parte de las autoridades y el incumplimiento de la debida diligencia en la investigación; además de la negativa de justicia e indemnizaciones dignas a los familiares (Corte Interamericana de Derechos Humanos, 2009). En consecuencia, la sentencia señala que en las investigaciones donde la víctima es una mujer se deberá tratar siempre con perspectiva de género, lo cual exige una constante capacitación de los servidores públicos encargados de la procuración de justicia.

La Fiscalía Especializada en Atención de Mujeres Víctimas del Delito por Razones de Género en el Estado (2012) actualmente se encarga de investigar de manera especializada los delitos cometidos contra mujeres por el solo hecho de ser mujer. Entonces, si esta Fiscalía se encarga 
únicamente de los delitos contra la mujer, podemos deducir que solamente atiende mujeres, mientras que las Fiscalías de Distrito atienden los demás casos, donde no se presentan cuestiones de género. Pero ¿qué sucede cuando la víctima es una mujer transgénero y el origen del delito es precisamente esta condición? "Objetivamente, el género está constituido por los aspectos psicosociales y las pautas culturales que una determinada sociedad atribuye como propias para cada sexo en un determinado momento histórico" (Alcaraz \& Alcaraz, 2008, p. 8); mientras que "transgénero" es un término especial, ya que alude a las personas cuyo sexo de nacimiento no coincide con las expectativas de género previamente asignadas por la sociedad (Scott, Cayleff, Donadey, \& Lara, 2017).

No solo se trata de analizar cuál de estas fiscalías llevará la investigación, sino también los preceptos legales en los que se encuadra la acción delictiva. En nuestro estado a "quien prive de la vida a una mujer por una razón de género [...] se le impondrá de cuarenta a sesenta años de prisión [...] y la reparación integral del daño" (Código Penal del Estado de Chihuahua, 2006, art. 126 bis.). Este tipo penal no especifica qué debe de entenderse por "mujer", es decir, sí biológicamente debe de ser una persona nacida mujer o si cabe la posibilidad de encuadrar víctimas que se conducían bajo dicho género, sin importar su sexo.
En todas las diligencias que se realicen para la búsqueda de la Persona Desaparecida o No Localizada, así como para investigar y juzgar los delitos previstos en esta Ley, se deberá garantizar su realización libre de prejuicios, estereotipos y de cualquier otro elemento que, por cuestiones de sexo, género, identidad u orientación sexual de las personas, propicien situaciones de desventaja, discriminación, violencia o se impida la igualdad (Ley General..., 2017, art. 5).

Este cuerpo legal sí contempla la debida diligencia libre de prejuicios incluyendo el sexo y el género, sin embargo, como en muchos otros ordenamientos jurídicos, se puntualizan de diferente manera ambos términos. Es aquí donde nos encontramos con lo que se conoce en el campo del derecho como "lagunas jurídicas", es decir, las instituciones de seguridad pública pueden actuar sin sustento y, por ende, los derechos humanos de las mujeres transgénero son susceptibles a ser vulnerados.

Tal vez este enfoque no sea muy relevante hoy en día, pues son pocos los casos de mujeres transgénero e incluso en varios lugares aún no son reconocidos sus derechos, pero en unos años lo será, máxime si se cuenta con el apoyo de los grupos sociales y de las organizaciones encargadas de vigilar el cumplimiento de los derechos humanos. Aparentemente lo de menos es canalizar el asunto a cualquiera de las fis- 
calías, pues los profesionales deben respetar la identidad de género de las personas a las que prestan el servicio, sin importar su apariencia física (Organización Panamericana de la Salud, 2012), no obstante, la perspectiva de género es pieza clave en la indagación, ya que un concepto puede cambiar por completo las líneas de investigación y de ellas depende que se esclarezcan los hechos. Actualmente no se encuentra especificado el enfoque que se le debe dar a las investigaciones de los casos de mujeres transgénero que son víctimas de un delito. La legislación penal vigente en el estado de Chihuahua y las instituciones encargadas de la procuración de justicia, en este caso la Fiscalía General del Estado de Chihuahua, no han establecido el tratamiento para su atención, lo que genera incertidumbre tanto en las víctimas como en los titulares de la investigación.

En una escena del crimen donde la víctima es mujer, se debe determinar si se trata de un homicidio o un homicidio por razones de género ("feminicidio"). Los peritos en Criminalística de Campo adscritos a la Dirección General de Servicios Periciales de la Fiscalía General del Estado, de acuerdo con las características del hecho - por ejemplo, si el cuerpo de la víctima presenta signos de violencia sexual o traumatismos, o si este estuvo expuesto o fue enterrado $u$ ocultado-, son quienes determinan la naturaleza del delito. Entonces, ¿qué sucede cuando en la misma escena, la víctima es una mujer transgénero?

Otro punto de igual relevancia para Ciudad Juárez ocurre cuando desaparece una mujer y los familiares interponen un reporte en la Fiscalía Especializada en Atención a Mujeres Víctimas del Delito por Razones de Género (2012). En este caso, el agente del Ministerio Público recaba la información necesaria e inicia una investigación para localizarla; además elabora una pesquisa que contiene una fotografía y los datos de la mujer ausente, tales como nombre, edad y sexo, la cual se publicará y se difundirá entre la sociedad y los medios de comunicación. Ahora, si la persona desaparecida es una mujer transgénero, ¿a dónde deben de acudir los familiares para que los atiendan debidamente? y ¿qué debe de hacer el Agente del Ministerio Público? No solo se trata de precisar el enfoque de la investigación, otros detalles también son importantes. Por ejemplo, al momento de elaborar la pesquisa, ¿debe de estar la persona legalmente reconocida por el Estado para señalar un sexo "femenino" o este debe ser "masculino"? y ¿qué fotografía se va a utilizar? Cualquier error podría violar los derechos fundamentales de la víctima y ponerla en un estado de vulnerabilidad grave.

En los próximos años, esta problemática se enfrentará con más frecuencia, sin embargo, actualmente no se encuentra tipificada ni existe un protocolo de actua- 
ción, se atiende estrictamente al sexo de la persona. En este orden de ideas, ¿están preparados los servidores públicos encargados de la procuración de justicia en Ciudad Juárez para atender casos de mujeres transgénero juzgando con perspectiva de género? La legislación penal vigente no contempla si a los casos de mujeres transgénero que son víctimas de un delito se les dará una atención con perspectiva de género o solo se considerarán las características biológicas y legales, es decir, haber nacido hombre. Lo anterior debe tener en cuenta que en el estado de Chihuahua existe una Fiscalía Especializada en Atención a Mujeres Víctimas del Delito por Razones de Género, por lo cual es imprescindible plantear lineamientos bajo los cuales perseguir e investigar dichos casos.

" $\mathrm{El}$ acceso a la justicia tiene un fuerte componente de servicio, pues debe ser el camino que une al individuo con el sistema judicial” (Insignares, 2015, p. 201). Es deber de los servidores públicos asegurar el acceso a la misma, pero si este no tiene claro su actuar en los caso de las mujeres transgénero o la ley no se lo indica, está dejando en un estado de vulnerabilidad los derechos de la víctima y violando todos los preceptos legales que facultan su actuar, es precisamente este punto el más importante.

Cabe destacar que no solo se trata de saber qué sexo poner en una pesquisa de una persona desaparecida, de investigar el homicidio de una mujer transgénero con perspectiva de género o de que el Estado reconozca su sexo mediante un papel. Es la vulnerabilidad de la víctima lo más importante, el riesgo que pueda sufrir frente a una situación de peligro y la responsabilidad de los servidores públicos; pues nunca será lo mismo el entorno familiar, social o laboral de una mujer al de una mujer transgénero. Además, ¿qué tal si el motivo del delito es precisamente esta condición? El primer respondiente no lo sabe, tampoco el Agente del Ministerio Público ni el Agente Ministerial, probablemente ni el Perito en Criminalística de Campo. Si ellos, que son profesionales, no lo saben, se está violando totalmente los derechos de la persona.

Por ello se considera importante conocer qué trato se les dará a las víctimas de un delito cuando son mujeres transgéneros, no se trata de una tendencia, un capricho o un certamen de belleza. Se trata de una realidad no muy lejana que la ley aún no contempla y las autoridades no tienen la capacitación ni experiencia para enfrentar. Es por todo lo anterior, que en la presente investigación analizo si los servidores públicos encargados de la procuración de justicia en Ciudad Juárez, Chihuahua, están verdaderamente preparados para atender casos de mujeres transgénero con base en la perspectiva de género. 


\section{Perspectiva de género: concepto}

A raíz de los hechos ocurridos en el año 2001 en el caso de Claudia Ivette González, Esmeralda Herrera Monreal y Laura Berenice Ramos Monárrez, familiares de las víctimas, con ayuda de representantes sociales, presentaron una demanda en contra del Estado mexicano ante la Comisión Interamericana de Derechos Humanos, y posteriormente ante la Corte Interamericana de Derechos Humanos. Esto derivó en una sentencia que obliga al Estado a optar diversos lineamientos, específicamente en Ciudad Juárez, Chihuahua. Uno de los puntos resolutivos de la sentencia fue crear una institución especializada en atención a delitos contra la mujer, así como la debida preparación de los servidores públicos en el tema de perspectiva de género, por lo que en el año 2012, se establece en el estado de Chihuahua la Fiscalía Especializada en Atención a Mujeres Víctimas del Delito por Razones de Género, la cual se encarga de proteger a aquellas mujeres que han sufrido algún tipo de agresión solo por la condición de ser mujer.

La diferencia entre los sexos, en teoría, no implica una desigualdad legal, sin embargo, la antes mencionada sentencia prevé el término "perspectiva de género". De acuerdo con la Ley General en Materia de Desaparición Forzada de Personas, Desaparición Cometida por Particulares y del
Sistema Nacional de Búsqueda de Personas (2017), juzgar con perspectiva de género significa "garantizar su realización libre de prejuicios, estereotipos y de cualquier otro elemento que, por cuestiones de sexo, género, identidad u orientación sexual de las personas, propicien situaciones de desventaja, discriminación, violencia o se impida la igualdad" (p. 5).

Una vez definido el significado de juzgar con perspectiva de género, así como la función de la fiscalía especializada y la necesidad de su creación, ¿qué sucede con aquellas mujeres transgénero que son víctimas de un delito? Antes que nada, debemos conceptualizar qué se entiende por sexo y género.

El concepto de "género" ha sido considerado uno de los puntos clave en el desarrollo de la teoría feminista, que distingue entre el sexo biológico y la socialización de la feminidad y la masculinidad, y eventualmente, de otras formas de identidad de género y deseo sexual (Lampert, 2017, p. 1).

Para efectos del presente trabajo, entenderemos que las características biológicas de cada persona determinan su sexo, ya sea masculino o femenino, mientras que el género se refiere a las características socioculturales reconocidas y atribuidas para el hombre y la mujer. "Al igual que otras nociones y paradigmas cardinales 
en la investigación sociocultural, no existe una definición unívoca del género, ya que su significado está sujeto a constantes precisiones" (Martín, 2006, p. 36).

Por otra parte, Maffía (2003) señala: "Más allá de esta variación en la terminología, la mayoría de la gente trans estaría de acuerdo con que su auto identificación es un derecho personal importante" (p. 34), como lo es el acceso a la justicia. "En toda investigación y proceso penal [...], las autoridades deben garantizar su desarrollo de manera autónoma, independiente, inmediata, imparcial, eficaz, y [deben ser] realizados con oportunidad, exhaustividad, respeto de derechos humanos y máximo nivel de profesionalismo" (Ley General..., 2017, p. 4).

\section{Delitos de género e instituciones mexi- canas encargadas de procuración de justicia}

En la actualidad ya no es posible encuadrarse en una dicotomía de identidad de género, no se puede enmarcar en una cuestión de hombre o mujer o de blanco o negro, las personas son seres individuales y como tal deben tratarse, no clasificarlas, no estigmatizarlas, no señalarlas; en otras palabras, no discriminarlas; por lo que, derivado de lo anterior es importante resaltar la responsabilidad que tienen los Estados de proteger a todas las personas (Unda, 2019, p. 6).
La Carta Magna señala: "La investigación de los delitos corresponde al Ministerio Público y a las policías, las cuales actuarán bajo la conducción y mando de aquél en el ejercicio de esta función" (Constitución Política de los Estados Unidos Mexicanos, 1917, art. 21). De acuerdo con el Código Nacional de Procedimientos Penales (2014):

Compete al Ministerio Público conducir la investigación, coordinar a las Policías y a los servicios periciales durante la investigación, resolver sobre el ejercicio de la acción penal en la forma establecida por la ley y, en su caso, ordenar las diligencias pertinentes y útiles para demostrar, o no, la existencia del delito y la responsabilidad de quien lo cometió o participó en su comisión (art. 127).

Por otra parte, el Código Penal del Estado de Chihuahua (2006), establece que:

El Poder Ejecutivo del Estado de Chihuahua, a través de la Fiscalía General del Estado, en el ámbito de su competencia y capacidades, de acuerdo al Resolutivo 18 de la Sentencia emitida por la Corte Interamericana de Derechos Humanos en el caso González y Otras ("Campo Algodonero") Vs. México, verificará la estandarización de sus protocolos para la investigación del Feminicidio (p.133).

Finalmente, en el Periódico Oficial del Gobierno del Estado de Chihuahua se publicó el siguiente decreto: 
La Fiscalía Especializada en Atención a Mujeres Víctimas del Delito por Razones de Género, tendrá a su cargo:

A. El ejercicio de las atribuciones a que se refiere el Apartado B del artículo 2 de esta Ley, cuando se trate de hechos en los que se haya privado de la vida a mujeres por razones de violencia de género; igualmente en los casos de los siguientes hechos o conductas delictivas en que la víctima sea mujer: a) Que atenten contra la libertad y seguridad sexual y el normal desarrollo psicosexual; b) Violencia familiar; c) Que atenten contra la obligación alimentaria; d) Desaparición de mujeres respecto de hechos no vinculados a la delincuencia organizada; y e) Discriminación por razones de género.

B. La atención psicológica, médica y otras, en los casos de violencia contra las mujeres en los delitos o hechos contemplados en el apartado A de este artículo, en coordinación con otros órganos o unidades administrativas de la Fiscalía General que proporcionen los servicios a que se refiere el presente apartado.

C. La canalización a Víctimas u ofendidos, en los casos de los apartados anteriores, hacia las dependencias o instituciones que proporcionen los servicios de carácter tutelar, asistencial, preventivo, educacional y demás de contenido similar, así como la vigilancia de su debida atención.
Este órgano estará a cargo de un Fiscal Especializado, quien contará con el apoyo de cuatro Coordinaciones Regionales de Ministerio Público y Policía Ministerial de Investigación del Delito, de las unidades administrativas necesarias y demás personal que requiera para el cumplimiento de sus funciones. En todo caso, el personal adscrito a esta Fiscalía deberá contar con el perfil especializado que corresponda a la naturaleza propia de sus funciones (Decreto $\mathrm{N}^{\circ}$. 733/2012, 2012, pp. 499-500).

El órgano encargado de la investigación y persecución de los delitos es el Ministerio Público, además, la legislación del estado de Chihuahua faculta a la Fiscalía General del Estado para conocer y establecer los protocolos adecuados para la investigación de delitos por razones de género. Haciendo uso de esta facultad y con base en la sentencia del "Campo Algodonero" (Corte Interamericana de Derechos Humanos, 2009), nace la Fiscalía Especializada en Atención a Mujeres Víctimas del Delito por Razones de Género, ahí se atienden delitos de violencia familiar, delitos de índole sexual, homicidios de mujeres por razones de género y reportes de ausencia o extravío.

No son lo mismo los delitos por razones de género que los delitos donde la víctima es una mujer, pero nada tienen que ver con el género. Retomando el ejemplo del delito de homicidio, si este es en contra de una mujer y durante la investigación, 
o incluso en la misma escena del crimen, se determina que el móvil del hecho es la delincuencia organizada, no estamos hablando de una cuestión de género, por lo tanto, no será la Fiscalía Especializada en Atención a Mujeres Víctimas del Delito por Razones de Género quien conozca del caso, sino la Fiscalía de Distrito. Lo mismo sucede en otros delitos como daños o lesiones, o incluso riñas, entre dos mujeres, no se trata de una cuestión de género, aunque la víctima sea precisamente una mujer. Es importante aclarar esta diferencia, ya que es común que se canalice erróneamente a los usuarios y en una situación de angustia por la comisión de un delito no es digno que las víctimas se trasladen innecesariamente de un edificio a otro por la falta de pericia de los servidores público. Si estos errores suceden en condiciones “normales”, ¿qué sucederá en los casos de las mujeres transgénero?

No en todos los estados de la república existe una fiscalía especializada de la mujer, cada fiscalía o procuraduría establece sus protocolos para los delitos de género de acuerdo con su realidad. Chihuahua es pionero en estas cuestiones. Segato (2004) considera que:

En particular Ciudad Juárez, estado de Chihuahua, frontera Norte de México con El Paso, Texas, es un lugar emblemático del sufrimiento de las mujeres. Allí, más que en cualquier otro lugar, se vuel- ve real el lema "cuerpo de mujer: peligro de muerte" (p. 3).

Se trata de un fenómeno único, favorecido por un entorno socioeconómico propicio, conformado por impunidad, violencia de género en un mundo patriarcal misógino, [...] ineficiencia policíaca, indiferencia, desigualdad, prejuicio, ignorancia, narcotráfico e intereses políticos. Este entorno se da en Ciudad Juárez, en el estado de Chihuahua, al norte de México (Álvarez, 2003, p. 220).

Las muertas de Juárez ha sido un tema a nivel mundial, la ciudad es reconocida por su marginación, violencia y machismo, lo que derivó en una condena por parte de un organismo internacional.

\section{Legislación internacional}

Las constituciones y leyes internacionales actuales contemplan que todas las personas tienen garantizados los mismos derechos, pero qué sucede con los derechos de las personas transgénero en la legislación de los países.

"La ley española fue la primera del mundo en reconocer plenos derechos a los cónyuges del mismo sexo, lo que facilitó la supresión de las limitaciones excepcionales que figuraban en las leyes de otros países" (Noir, 2010, p. 137). Este acontecimiento fue de gran importancia para la legislación española y de otras naciones, pues establece un derecho fundamental de las 
parejas del mismo sexo y da pie a más reconocimientos por parte del Estado, como la Ley 2/2016, de 29 de marzo, de Identidad y Expresión de Género e Igualdad Social y no Discriminación de la Comunidad de Madrid (2016), la cual define a las personas trans como:

Toda aquella persona que se identifica con un género diferente o que expresa su identidad de género de manera diferente al género que le asignaron al nacer. A los efectos de esta Ley y sin prejuzgar otras acepciones sociales el término trans ampara múltiples formas de expresión de la identidad de género o subcategorías como transexuales, transgénero, travestis, variantes de género, queer o personas de género diferenciado, así como a quienes definen su género como "otro" o describen su identidad en sus propias palabras (p. 9).

Además de la Ley 4/2018, de 19 de abril, de Identidad y Expresión de Género e Igualdad Social y no Discriminación de la Comunidad Autónoma de Aragón (2018) indica:

Ninguna persona podrá ser objeto de discriminación, acoso, penalización o castigo por motivo de su identidad o expresión de género. En particular, las personas deben ser tratadas de acuerdo con su identidad de género manifestada, que es como la persona se presenta ante la sociedad, con independencia de su sexo legal, y así obrarán las instituciones y Administraciones públicas aragonesas en todos y cada uno de los casos en los que participen (p. 14).

Es decir, no solo tenemos un antecedente histórico en cuanto a los derechos de las personas transgénero, sino que existen ya varias leyes que los regulan. En Estados Unidos, si bien no hay legislaciones tan precisas como en España, recientemente la Corte Suprema de EE. UU. prohibió la discriminación en el trabajo de personas homosexuales y transgénero, lo que representa un gran avance para estas minorías, pues recordemos que este es un país hermético en cuanto a los temas de discriminación y derechos humanos. Por otro lado, en países latinoamericanos, los avances han sido mínimos.

En Colombia, sus avances en materia de dignidad humana, igualdad y justicia han sido lentos y opacados por las fobias de algunos grupos e individuos intolerantes a la diferencia y opuestos radicalmente a que los demás seres humanos obtengan sus mismos derechos y se encaminen a desarrollar su vida con total normalidad (Cardona-Cuervo, 2016, p. 91).

En Puerto Rico, la legislación a favor de los derechos de las personas identificadas LGBT cada día carece más de peso y 
esencia. Para proteger los derechos de este grupo minoritario sólo existe el Artículo 66 inciso (q) del Código Penal del año 2012, que señala los agravantes de delitos. En específico, este artículo crea condiciones para aumentar las sanciones para un delito que se llevó a cabo, hacia o contra la víctima por razón de raza, color, sexo, orientación sexual, género, identidad de género, origen, origen étnico, estatus civil, nacimiento, impedimento o condición física o mental, condición social, religión, edad, ideologías políticas o creencias religiosas, o ser persona sin hogar (Rivera, Toro-Alfonso, \& Melendez, 2013, p. 5).

En México, como en otros países de Latinoamérica, el progreso ha sido lento en comparación con países europeos que desde hace muchos años debidamente han "normalizado" estás orientaciones sexuales. Sin embargo, el trabajo realizado por parte del legislador, como ya se precisó con anterioridad, es de reconocerse, aunque sea como resultado de la sentencia del “Campo Algodonero" (Corte Interamericana de Derechos Humanos, 2009).

\section{Método del tópico de investigación}

La presente investigación aborda una estrategia cualitativa porque "se enfoca en comprender los fenómenos, explorándolos desde la perspectiva de los participantes en un ambiente natural y en relación con su contexto" (Hernández, Fernández, \& Baptista, 2014, p. 358). Se trata de una exploración transversal porque los datos analizados fueron obtenidos de una población específica y por un periodo de tiempo determinado (Marketing E-nquest, 2018); descriptiva e interpretativa, ya que fue necesario descifrar la realidad desde la óptica de cada objeto de estudio y así evaluar su actuar. Para ello se empleó una muestra no probabilística por conveniencia de 32 participantes considerando como sujeto de análisis a los agentes del Ministerio Público, agentes de la Agencia Estatal de Investigación y agentes de la Comisión Estatal de Seguridad de la Fiscalía General del Estado, Zona Norte; así como a los agentes de la Secretaria de Seguridad Pública de Ciudad Juárez, Chihuahua, los cuales fueron seleccionados de acuerdo con el grado de servicio dentro la corporación.

Como técnica de recolección de datos se utilizó una entrevista estructurada con diez preguntas, las cuales midieron la perspectiva de género desde un punto de vista aplicativo y permitieron concentrar la opinión de los sujetos en cuanto al problema de investigación, así como determinar si realmente los servidores públicos están siguiendo los lineamientos que indica la ley. Esta entrevista se realizó bajo el consentimiento informado de cada uno de los participantes, de manera individual, vía remota y con un tiempo aproximado de 10 minutos. Cabe mencionar que los mis- 
mos fueron adultos de entre 30 y 40 años, hombres y mujeres en igual número, algunos de ellos solteros y otros casados, todos con una licenciatura concluida. Todos son agentes activos en las ya mencionadas corporaciones y su rol dentro de las mismas es imprescindible para la efectiva procuración de justicia.

\section{Interpretación a partir de las entrevistas}

De los resultados obtenidos se destaca que, 25 de los 32 entrevistados coinciden en que el sexo define biológicamente a los seres humanos como hombres y mujeres, mientras que el género hace referencia al papel que se desempeña en sociedad de acuerdo con los roles que históricamente se han asignado como masculinos y femeninos, por lo que los participantes afirman que el género es, sin lugar a duda, una construcción social y cultural. Solo 11 de los participantes reconocen el significado de juzgar con perspectiva de género y la situación de desventaja en la que se encuentran las mujeres. Varios respondientes manifestaron no conocer este concepto, lo confunden con las prácticas discriminatorias y el acceso a la justicia.

En cuanto a la violencia de género, la mitad de los sujetos coinciden en que esta se origina contra la mujer por el solo hecho de serlo. Además, distinguen que deben considerarse como delitos por razones de género la violencia familiar, los delitos de índole sexual y los "feminicidios"; incluso los par- ticipantes propusieron algunos otros que no se encuentran en la legislación actual como la desaparición forzada de mujeres y el acoso laboral. Dos personas manifestaron no estar de acuerdo con esta clasificación y consideran que todos los delitos deben de ser juzgados como tal, independientemente de si la víctima es un hombre o una mujer. Sobre el alcance de este tipo de disposiciones, 17 de los 32 respondientes coinciden en que se pretende proteger la integridad y la dignidad de las mujeres.

Consideran que se debe atender el sexo biológico de la víctima en los casos de delitos de género 22 de los participantes y tan solo dos que se debe valorar el género no el sexo; mientras que un participante indicó que a todas las personas se les debe dar la misma atención, sin importar su sexo o género, volviendo al tema de la discriminación. Finalmente, 27 de los participantes opina que la creación de una Fiscalía Especializada en Atención a Mujeres Víctimas del Delito por Razones de Género ha sido una buena e incluso necesaria estrategia para tratar de manera especializada los delitos por razones de género, dentro de este porcentaje, una persona opina que lo justo sería que también se creara una institución similar para hombres, puesto que tanto hombres como mujeres están expuestos.

No se puede hablar de mujeres transgénero sin una visión amplia de perspectiva de género y, sobre todo, el reconocimiento 
de la desigualdad estructural que durante años han vivido. De esta manera, fue fundamental, antes que nada, conocer la óptica personal de cada uno de los participantes en cuanto a los delitos de género se refiere. Después de realizar 32 entrevistas a elementos de las distintas corporaciones ya mencionadas, se observa que la gran mayoría conoce la diferencia entre sexo y género, y es precisamente este el punto de partida para juzgar con perspectiva de género.

Asimismo, casi la totalidad de los participantes coincidieron en que los delitos de violencia familiar, los delitos sexuales, la trata de personas y los homicidios por razones de género o "feminicidios" son delitos graves y deben tratarse como tal. Aunque hubo algunos respondientes que manifestaron no estar de acuerdo con estas clasificaciones, sus opiniones iban encaminadas a que tanto hombres como mujeres deben de recibir el mismo trato sin ningún tipo de discriminación. Es de resaltar que la tipificación "especial" que contiene nuestra legislación penal de delitos contra la mujer no es discriminatoria en ninguno de sus apartados. Si bien es cierto que tanto hombres como mujeres tenemos los mismos derechos como víctimas, también es cierto que los derechos de las mujeres históricamente se han visto vulnerados. Basta con profundizar en el pasado para darse cuenta de que existe una supremacía masculina, pues fue hasta el año de 1996 cuando se reconoció que "los derechos de las mujeres son derechos humanos" (Naciones Unidas, 1996, p. 3). Somos testigos de que a las mujeres las matan después de haber abusado sexualmente de ellas, esta es la razón por la cual nuestra legislación señala una penalidad agravante o "especial" en este tipo de crímenes, no es que la vida la mujer tenga más valor.

A pesar de ello, se advierte que el problema no es el desconocimiento en los temas de género ni la legislación, se trata de la falta de reconocimiento institucional, de la praxis. Esto quedó claro al preguntar: ¿existen obstáculos para la incorporación de la perspectiva de género en sus investigaciones? La mayoría de los participantes comentó que estos existen dentro del área laboral, lo que es verdaderamente preocupante. No se sabe con exactitud si estos obstáculos son personales o se deben a órdenes superiores o simplemente a la naturaleza de sus funciones. Sea cual sea la causa, no se juzga con perspectiva de género: el Estado mexicano no está cumpliendo con la sentencia del "Campo Algodonero" (Corte Interamericana de Derechos Humanos, 2009) y mucho menos está preparado para atender delitos donde la víctima es una mujer transgénero.

Finalmente, en cuanto a la creación de la Fiscalía Especializada en Atención a $\mathrm{Mu}$ jeres Víctimas del Delito por Razones de Género, se externaron diversas opiniones. La mayoría de los participantes manifes- 
taron estar de acuerdo con su creación, mientras que otros sugieren que así como existe una fiscalía para la mujer también debería existir una para el hombre. Hubo otros más que ni siquiera sabían de su existencia. Entonces, ¿qué sucede cuando deben atender a una mujer víctima de un delito? ¿a dónde la canalizan? Si los operadores del mismo sistema no saben que existe una institución especializada para atender las cuestiones de género, ¿qué se puede esperar de la sociedad? Además, ¿es necesario crear una fiscalía especializada para hombres después de analizar el contexto histórico y cultural de la desigualdad entre hombres y mujeres? Solo estamos evidenciando el total desconocimiento de las cuestiones de género y de la propia ley.

\section{Reflexiones finales}

El objetivo del presente trabajo de investigación fue analizar si los operadores del sistema de impartición y procuración de justicia en Ciudad Juárez, Chihuahua, es decir, agentes del Ministerio Público, agentes de la Agencia Estatal de Investigación, agentes de la Comisión Estatal de Seguridad de la Fiscalía General del Estado, así como los agentes municipales de la Secretaría de Seguridad Pública Municipal, actúan con perspectiva de género en los casos donde la víctima es una mujer transgénero. Es importante iniciar con la visión de cada de uno de los operadores para posteriormente hablar de una institución, no solo se trata de servidores públicos y de instituciones de procuración de justicia, sino de cualquier lugar en el que una mujer sea discriminada por el solo hecho de serlo.

Hoy en día se reconoce el esfuerzo de las instituciones de seguridad pública por incorporar la perspectiva de género dentro de sus ámbitos de competencia, desde la constante capacitación de los operadores hasta la creación de áreas o unidades especializadas, no obstante, aún falta mucho trabajo por hacer. La sentencia del “Campo Algodonero” (Corte Interamericana de Derechos Humanos, 2009) es muy clara, la ley también; pero de nada sirve la creación de lineamientos perfectos si al momento de recibir una denuncia se culpa a la víctima, ya sea por ser mujer, por ser mujer transgénero o por cualquier otra condición: esto convierte a la praxis en una verdadera falacia.

En este escenario todos son jueces y antes de investigar el nombre del agresor parece que es necesario saber el tamaño de la falda de la víctima si se trata de una violación o si andaba de fiesta el día que la privaron de la vida. Esto es absurdo porque existen casos de bebés que lamentablemente son abusados sexualmente cuando no había nada de "provocativo" en ellos o qué decir de las mujeres musulmanes.

¿Será que el respeto hacia los derechos de la mujer se origina desde el hogar, atendiendo a los valores y costumbres de cada persona?, ¿ o realmente es algo que se 
aprende con el tiempo? Es urgente normalizar estos derechos, reconocer que siempre han existido y que tanto las autoridades como la sociedad nutran ese ánimo de solidaridad y cooperación que acrecenté el concepto de mujer en el mundo (Naciones Unidas, 1996).

\section{Bibliografía}

Alcaraz, R., \& Alcaraz, A. (2008). El derecho a la no discriminación por identidad y expresión de género. Ciudad de México: Arturo Cosme Valadez.

Álvarez, J. (2003). Las muertas de Juárez: bioética, género, poder e injusticia. Acta Bioethica, 9(2), 219-228. DOI:http://dx.doi. org/10.4067/S1726-569X2003000200008

Cardona-Cuervo, J. (2016, julio-diciembre). La construcción de los derechos del grupo social transgénero. Entramado, 12(2), 84-95. http://dx.doi.org/10.18041/entramado.2016v12n2.24202

Código Nacional de Procedimientos Penales (2014, 5 de marzo). Diario Oficial de la Federación. http://www.diputados.gob.mx/LeyesBiblio/pdf/CNPP_190221.pdf

Código Penal del Estado de Chihuahua (2006, 27 de diciembre). Periódico Oficial (103). http://www.congresochihuahua2.gob.mx/ biblioteca/codigos/archivosCodigos/64.pdf Constitución Política de los Estados Unidos Mexicanos (1917). Artículo 21. Última reforma DOF 18-06-2008. https://museodelasconstituciones.unam.mx/constitucion/articulo-21o/
Corte Interamericana de Derechos Humanos (2009, 16 de noviembre). Caso González y otras ("Campo Algodonero") vs. México. https://www.corteidh.or.cr/docs/casos/articulos/seriec_205_esp.pdf

Decreto Nº. 733/2012 (2012, 4 de febrero). Periódico Oficial del Gobierno del Estado de Chihuahua. http://www.chihuahua.gob.mx/ atach2/po010_2012.pdf

Fiscalía Especializada en Atención a Mujeres Víctimas del Delito por Razones de Género. (2012). Fiscalía General del Estado. http://fiscalia.chihuahua.gob.mx/inicio/?page_id $=46$ Hernández, R., Fernández, C., \& Baptista, P. (2014). Metodología de la Investigación ( $6^{\mathrm{a}} \mathrm{ed}$.). Ciudad de México: Mc Graw Hill.

Insignares, S. (2015, enero-junio). El acceso a la justicia a partir del mecanismo de solución de controversias previsto en el TLC COLUSA. Revista de Derecho (43), 197-236. https:// www.redalyc.org/pdf/851/85138494007.pdf

Lampert, M. (2017,14 de septiembre). Evolución del concepto de género: identidad de género y la orientación sexual. Biblioteca del Congreso Nacional de Chile. https://www.camara.cl/ verDoc.aspx?prmTIPO=DOCUMENTOCOMUNICACIONCUENTA\&prmID $=56104$

Ley $2 / 2016$, de 29 de marzo, de Identidad y Expresión de Género e Igualdad Social y no Discriminación de la Comunidad de Madrid (2016). Legislación de la Comunidad de Madrid. http://www.madrid.org/wleg_pub/ servlet/Servidor?opcion=VerHtml\&nmnor$\mathrm{ma}=9264$ 
Ley 4/2018, de 19 de abril, de Identidad y Expresión de Género e Igualdad Social y no Discriminación de la Comunidad Autónoma de Aragón (2018, 30 de mayo). Boletín Oficial del Estado (131). https://www.boe.es/buscar/ pdf/2018/BOE-A-2018-7154-consolidado.pdf

Ley General en Materia de Desaparición Forzada de Personas, Desaparición Cometida por Particulares y del Sistema Nacional de Búsqueda de Personas (2017, 17 de noviembre). Diario Oficial de la Federación. http:// www.diputados.gob.mx/LeyesBiblio/pdf/LGMDFP_190221.pdf

Maffía, D. (2003). Sexualidades migrantes: género y transgénero. Buenos Aires: Librería de Mujeres.

Marketing E-nquest (2018, 20 de agosto). ¿Qué es un estudio Transversal? E-nquest. https://www.e-nquest.com/que-es-un-estudio-transversal/

Martín, A. (2006). Antropología del género: culturas, mitos y estereotipos sexuales. Madrid: Cátedra.

Naciones Unidas. (15 de Septiembre de 1996). Informe de la cuarta conferencia mundial sobre la mujer: Beijing, 4 a 15 de septiembre de 1995. https://www.un.org/womenwatch/daw/beijing/pdf/Beijing\%20full\%20report\%20S.pdf Noir, R. (2010, marzo-abril). Sobre el movimiento LGHBT Lésbico-Gay-Homosexual-Bisexual Transgénero. Revista Electrónica de Psicología Política (22). http://www.psicopol. unsl.edu.ar/abril2010_Nota8.pdf

Organización Panamericana de la Salud (2012). Por la salud de las personas trans: ele- mentos para el desarrollo de la atención integral de personas trans y sus comunidades en Latinoamérica y el Caribe. https://www. paho.org/arg/images/gallery/Blueprint $\% 20$ Trans\%20Espa\%C3\%83\%C2\%B1ol.pdf

Rivera, C., Toro-Alfonso, J., \& Melendez, L. (2013). Minorías frente al alza en la criminalidad: percepción de seguridad de la comunidad lesbiana, gay, bisexual y transgénero (LGBT) en Puerto Rico. Revista Puertorriqueña de Psicología, 24(2). http://www. ojs.repsasppr.net/index.php/reps/article/ view/222/222

Scott, B., Cayleff, S., Donadey, A., \& Lara, I. (2017). Women in culture: an intersectional anthology for gender and women's studies. Ilinois: Wiley Blackwell.

Segato, R. (2004). Territorio, soberanía y crímenes de segundo Estado: la escritura en el cuerpo de las mujeres asesinadas en Ciudad Juárez. Brasilia: Universidade de Brasília.

Unda, M. (2019). Los derechos humanos de las personas transgénero. Tesis de maestría. Universidad Iberoamericana, Ciudad de México. http://ri.ibero.mx/bitstream/handle/ibero/2508/016811s.pdf?sequence $=1$ 